\title{
CONTRATOS MINEROS: COMENTARIOS SOBRE CLÁUSULAS PARA FACILITAR LA EJECUCIÓN DE PROYECTOS MINEROS
}

\author{
HERnÁN TORRES ÁLVAREZ* \\ Universidad de Lima, Lima, Perú \\ Recibido: 16/11/2020 Aceptado: 1/12/2020 \\ doi: https://doi.org/10.26439/iusetpraxis2021.n053.4968
}

\begin{abstract}
RESUMEN. En este trabajo se proponen ciertas cláusulas que pueden ser incluidas en los principales contratos mineros celebrados en el contexto de la ejecución de proyectos mineros. Para ello, primero, se describen las principales etapas del ciclo minero para ubicar en cuáles de ellas se negocian y celebran dichos contratos. Posteriormente, sobre la base de escenarios generales, se detallan los contratos necesarios y las cláusulas que podrían ser incorporadas en ellos para asegurar los intereses de las partes desde el punto de vista del negocio minero.
\end{abstract}

PALABRAS CLAVE: contrato minero / opción / cesión / transferencia / regalía / concesión

\section{MINING AGREEMENTS: COMMENTS REGARDING CLAUSES TO SECURE THE PERFORMANCE OF MINING PROJECTS}

\begin{abstract}
This article proposes certain clauses to be included in the main mining agreements that are executed for mining projects. For this purpose, the main stages of the mining cycle are described to identify in which of them these agreements are negotiated and executed. Later, based on general scenarios, the necessary agreements and clauses to be included in such agreements to secure the parties' interests from a mining business point of view are included.
\end{abstract}

KEYWORDS: mining agreement / option / lease / transfer / royalty / concession

\footnotetext{
* Abogado por la Pontificia Universidad Católica del Perú. Magíster en Legislación y Política Ambiental de Recursos Naturales por Sturm College of Law de la Universidad de Denver, Estados Unidos. Consultor externo de empresas mineras nacionales e internacionales en derecho minero, civil y corporativo. Profesor de derecho civil y minero en la Universidad de Lima, en la Universidad de Piura y en la Universidad Peruana de Ciencias Aplicadas (UPC). Consultor de la Cámara Minera del Perú.
} 
"Cumplido el ofrecimiento de Atahualpa, fundido, ensayado y repartido el oro, según Pedro Pizarro el gobernador dio por libre a Atahualpa y lo absolvió".

Rogger Ravines, El Cuarto del Rescate de Atahualpa 1532-1986

\section{INTRODUCCIÓN}

Iniciamos estos comentarios con una referencia al que podría ser el antecedente histórico más remoto del que tenemos noticia respecto de una transacción o contrato vinculado a la minería en el Perú: el episodio del Cuarto del Rescate, en el cual el inca Atahualpa ofreció por su libertad dos cuartos de plata y uno de oro. Hoy en día, las transacciones comerciales relacionadas con la minería son mucho más complejas, como describiremos a continuación.

En este trabajo vamos a comentar algunas de las cláusulas más importantes que usualmente son incorporadas en los contratos mineros ${ }^{1}$, en particular, en aquellos que son celebrados para la ejecución de proyectos mineros, con el objetivo de asegurar los intereses de las partes. Para ello, consideramos oportuno, primero, presentar el contexto necesario e identificar en cuál de las fases del ciclo minero estaría situado el proceso de negociación y celebración de estos contratos.

El ciclo minero apunta a lograr una finalidad muy específica: explotar yacimientos de minerales. Con este fin, la lógica que siguen las etapas de este ciclo se enfoca en encontrar el yacimiento, explotarlo y restaurar el ámbito en el que se desarrolló la actividad minera. En consecuencia, las cuatro principales etapas del ciclo minero son exploración, desarrollo, explotación/procesamiento y cierre de minas.

La primera etapa está comprendida por el cateo $^{2}$, la prospección ${ }^{3}$ y la exploración propiamente dicha ${ }^{4}$, y tiene como objetivo ubicar un yacimiento que sea económicamente explotable, conocer sus características, determinar la forma de explotarlo y calcular el valor e inversión requerida, entre otros aspectos que están detallados en lo que se

1 Para efectos de este trabajo, entendemos como contratos mineros aquellos que tienen por objeto derechos mineros (petitorios o concesiones mineras), ya sea para su transferencia, cesión o constitución de gravámenes.

2 De acuerdo con lo establecido en el artículo 1 del Decreto Supremo 014-92-EM, Texto Único Ordenado de la Ley General de Minería (en adelante, el TUO), el cateo es la acción conducente a poner en evidencia indicios de mineralización por medio de labores mineras elementales.

3 De acuerdo con lo establecido en el artículo 1 del TUO, la prospección es la investigación conducente a determinar áreas de posible mineralización, por medio de indicaciones químicas y físicas, medidas con instrumentos y técnicas de precisión.

4 De acuerdo con lo establecido en el artículo 8 del TUO, la exploración es la actividad minera tendente a demostrar las dimensiones, posición, características mineralógicas, reservas y valores de los yacimientos minerales. 
conoce como un estudio de factibilidad 5 . La segunda etapa implica que se ha descubierto un yacimiento minero económicamente explotable y consiste en construir la infraestructura necesaria para la extracción y procesamiento (por ejemplo, la ejecución de obras de adecuación del terreno para realizar el tajo; construir la planta de beneficio, campamentos, vías de acceso, infraestructura para el suministro de electricidad, agua, entre otros). Culminado el desarrollo de la mina, comienza la tercera y más larga de las etapas del ciclo minero: la explotación y procesamiento del mineral extraído, que consiste en la puesta en la superficie del mineral, su concentración y purificación, lo cual se logra mediante las actividades de beneficio, fundición y refinamiento. En esta etapa, se obtienen los beneficios económicos más importantes tanto para los inversionistas como para el Estado por la recaudación de impuestos y el impacto en la economía ${ }^{6}$. La duración de esta etapa depende de la vida útil de la mina, es decir, de la cantidad de mineral económicamente extraíble ${ }^{7}$ o su viabilidad económica, lo que se halla en función de la ley de corte o cut-off, esto es, la ley mínima del mineral que no originará pérdida en su explotación (Seinfeld et al., 1998, p. 125). Terminada la actividad de extracción, inicia la última etapa: el cierre de minas, cuyo objetivo es procurar reponer el estatus del área en la que se desarrolló la actividad a su estado anterior.

En las cuatro etapas mencionadas existen oportunidades para hacer diferentes tipos de negocios. Por ejemplo, en la fase de exploración, las empresas mineras junior ${ }^{8}$ venden proyectos mineros para que posteriormente sean desarrollados por empresas mineras major. En la etapa de desarrollo, las oportunidades de negocios están dadas principalmente para los contratistas mineros, quienes diseñan y construyen la infraestructura necesaria y la planta que será operada por las empresas mineras, obteniendo sus ganancias por los servicios que prestan. En la explotación y procesamiento de minerales existen dos rubros principales de negocios. El primero corresponde a la comercialización de los diversos productos generados en esta etapa (durante la explotación, la comercialización de minerales; durante el beneficio, la de concentrados; y durante la fundición y el refinamiento, la de commodities), en la cual intervienen, de un lado, las

5 Para mayores detalles, véase el Glosario técnico minero (Ministerio de Minas y Energía de Colombia, 2015).

6 En promedio, usualmente la minería aporta un $10 \%$ en el PBI de nuestro país.

7 La viabilidad económica para extraer un mineral está en función de su ubicación, profundidad, ley del mineral (es decir, la concentración que tenga en el subsuelo), costos de construcción de la infraestructura (CAPEX), costos de operación (OPEX), cotización de los minerales, entre otros. A partir de estos factores se determina la cantidad de minerales que podrá extraerse de un yacimiento determinado, puesto que no será posible extraer el $100 \%$ del mineral de manera que sea económicamente viable. El cambio en los factores antes mencionados podría hacer que la cantidad de mineral económicamente extraíble aumente o disminuya.

8 Este tipo de empresas usualmente se dedican a realizar actividades de exploración y vender proyectos mineros que cuenten con estudios de prefactibilidad a empresas mineras major, que disponen de capitales importantes para desarrollar y operar el proyecto. 
empresas mineras (de gran, mediana y pequeña minería ${ }^{9}$ y, de otro, aquellas conocidas como traders mineros, que están dedicadas únicamente a la comercialización de minerales, y no desarrollan actividades mineras ${ }^{10}$. Otro rubro de negocios en esta etapa consiste en la venta y adquisición de proyectos mineros en marcha. Por ejemplo, es común que un fondo de inversión minero adquiera un proyecto para incrementar su valor y posteriormente lo venda para que el fondo bajo su administración se incremente. Otro caso puede darse cuando una compañía minera en busca de financiamiento para desarrollar un proyecto vende aquellos que no sean de su interés a terceras empresas dispuestas a desarrollarlos. Finalmente, en la etapa de cierre pueden darse también oportunidades de negocio, por ejemplo, con la comercialización de relaves ${ }^{11}$ de minerales.

\section{PROPUESTAS DE CLÁUSULAS QUE PUEDEN SER INCLUIDAS EN CONTRATOS MINEROS PARA DESARROLLAR PROYECTOS}

Los contratos mineros a los que nos referimos en la introducción de este trabajo se encuentran principalmente en las etapas de exploración y explotación/beneficio, en los casos en los que se transfiera un proyecto minero para posteriormente ser desarrollado y explotado, o aquellos en los que se transfiere una operación en marcha. Para comentar las cláusulas que podrían agregarse a dichos contratos, vamos a plantear dos escenarios.

\section{Escenario 1}

En el escenario 1, tenemos una empresa minera junior A que ha explorado tres concesiones mineras (en adelante, las concesiones), cuenta con un estudio de prefactibilidad, y está lista para salir al mercado y vender este proyecto. Un potencial interesado (la empresa minera B) está dispuesto a adquirir las concesiones, pero antes quiere completar la exploración directamente para definir las características exactas de este yacimiento y la viabilidad económica de su explotación (asumamos para este escenario que el plazo necesario para terminar la exploración es de ocho años). La empresa A querrá asegurar, en caso de que transfiera sus concesiones a $\mathrm{B}$, el pago de una contraprestación en función de la cantidad de mineral extraído efectivamente.

9 Son consideradas empresas de gran minería aquellas que explotan diariamente más de 5000 toneladas; de mediana minería, entre 500 y 5000 toneladas; y de pequeña minería, menos de 500 toneladas (Seinfeld et al., 1998, p. 129).

10 La ganancia de estas empresas está en comprar minerales a bajos precios y venderlos a precios mayores.

11 Los relaves son los materiales resultado de diversos procesos de concentración de minerales. Si bien es cierto que contienen sustancias peligrosas, también están formados por minerales que podrían ser extraídos luego de un proceso de beneficio. Por eso son de interés para un cierto tipo de empresas mineras, en especial, las pequeñas. 
En este escenario, para lograr la transición de las concesiones de A hacia B, se requeriría celebrar los siguientes contratos mineros: (i) uno de opción de transferencia (para asegurar a B que durante el tiempo que sea necesario para completar los trabajos de exploración podrá adquirir las concesiones y, en caso de que sean transferidas a terceros en dicho tiempo, estos respeten la opción); (ii) uno de cesión minera (para que B cuente con un título habilitante que le permita realizar las actividades de exploración directamente en las concesiones y, con base en los resultados obtenidos, decidir si ejerce la opción); y (iii) uno de transferencia (para que, una vez ejercida la opción, se transfieran las concesiones a favor de B). Cabe indicar que los dos primeros contratos deberán celebrarse simultáneamente, mientras que el tercero sería celebrado en la etapa final de esta transacción, de ser el caso.

Vamos a comentar algunas de las cláusulas que consideramos importante incluir en estos contratos para lograr los objetivos que las partes persiguen en esta transacción desde el punto de vista del negocio minero; hacemos la salvedad de que no pretendemos cubrir todas las cláusulas civiles, tributarias, entre otras, que serían fundamentales, ni tampoco hacer el análisis de las distintas estructuras corporativas que podrían implementarse para este negocio (como, por ejemplo, la celebración de contratos de joint venture, earn-in, farm-in, entre otros) ${ }^{12}$. Antes de ello, vamos a comentar algunos aspectos generales sobre los contratos mineros para tener un contexto de sus principales características, en particular, aquellas vinculadas con este trabajo.

Los contratos mineros son aquellos que se encuentran tipificados por el TUO y les son aplicables las disposiciones del Código Civil. Son contratos consensuales que requieren de una formalidad ad probationem para que puedan ser oponibles frente a terceras partes y el Estado. Esta formalidad exige que sean elevados a escritura pública y que se inscriban en los Registros Públicos. En caso de que no se cumpla con tal formalidad, solo serán oponibles entre las partes. Por ello, al momento de redactar estos contratos, es conveniente incluir los requerimientos para su inscripción establecidos en el Reglamento de Inscripciones del Registro de Derechos Mineros. Si bien es cierto que los contratos mineros están tipificados por el TUO, esta tipificación no es numerus clausus, por lo que es posible que se pacten modalidades contractuales distintas de las reguladas expresamente. También cabe precisar que los contratos mineros pueden tener por objeto los distintos tipos de concesiones ${ }^{13}$ reguladas por el TUO, así como petitorios mineros. Finalmente, será necesario que los derechos mineros objeto de estos contratos estén previamente inscritos (en el caso de los petitorios mineros, como anotaciones preventivas).

12 Cabe mencionar que estas propuestas son el resultado de la casuística que hemos tenido a lo largo de muchos años de ejercer la práctica profesional en esta especialidad.

13 Es decir, concesiones de transporte, beneficio, labor general. 


\section{Contrato de opción de transferencia}

Como comentamos anteriormente, el contrato de opción de transferencia (en adelante, COT) es un contrato preparatorio que permite asegurar a B adquirir las concesiones en caso de que los resultados de la exploración sean positivos. A continuación, mencionamos ciertos aspectos que deberían ser incluidos en este contrato.

- Plazo de la opción

Para que el escenario 1 sea exitoso, el COT deberá mantenerse vigente por lo menos durante toda la etapa de exploración, es decir, ocho años. Sin embargo, el artículo $165^{14}$ del TUO establece que el plazo máximo de vigencia del contrato de opción minera es de cinco años, por lo cual, en este caso, se tendrían tres años no cubiertos por el COT. Para salvar esta situación, antes de finalizar el plazo de cinco años del COT, debería celebrarse un nuevo contrato por un plazo de tres años para cubrir el plazo total de exploración. Pero ello podría generar una contingencia en caso de que $A$ decida no celebrar un nuevo contrato. Ante dicho escenario contingente se podrían plantear las siguientes soluciones ${ }^{15}$ :

i. Celebrar dos contratos de opción, uno con un plazo de cinco años y el otro con un plazo de tres años, cuyo cómputo iniciaría una vez vencido el plazo del primer contrato.

ii. Que A otorgue un poder a favor de B para que este, en representación del primero, celebre un nuevo COT por el plazo restante que tenga las siguientes características: (a) que sea un poder irrevocable ${ }^{16}$; (b) que autorice expresamente a celebrar contratos a favor de sí mismo en virtud de lo establecido en el artículo $166^{17}$ del Código Civil; y (c) que esté sujeto a una condición suspensiva que consista en la negativa de A para celebrar el segundo COT $^{18}$.

14 TUO. Artículo 165.- Por el contrato de opción, el titular de una concesión se obliga, incondicional e irrevocablemente, a celebrar en el futuro un contrato definitivo, siempre que el opcionista ejercite su derecho de exigir la conclusión de este contrato, dentro del plazo estipulado. El contrato de opción deberá contener todos los elementos y condiciones del contrato definitivo, pudiendo pactarse que la opción puede ser ejercitada indistintamente por cualquiera de las partes. El contrato de opción minera se celebrará por un plazo no mayor de cinco años [cursivas añadidas], contado a partir de su suscripción.

15 Descartamos la posibilidad de pactar una cláusula de renovación automática, dado que es muy probable que la inscripción de este contrato en el Registro de Derechos Mineros sea observada con el argumento de que se pretende exceder el límite del plazo establecido en el artículo 165 del TUO.

16 De acuerdo con lo establecido en el artículo 149 del Código Civil, el poder puede ser revocado en cualquier momento, por lo cual debería otorgarse un poder irrevocable a fin de que A no pueda revocarlo en cualquier momento.

17 Según este artículo, es anulable el acto jurídico que el representante concluya consigo mismo, en nombre propio o como representante de otro, a menos que la ley lo permita, que el representado lo hubiese autorizado específicamente, o que el contenido del acto jurídico hubiera sido determinado de modo que excluya la posibilidad de un conflicto de intereses. En tal sentido, en este caso, A deberá autorizar expresamente a B a celebrar consigo mismo el COT.

18 De acuerdo con lo establecido en el artículo 153 del Código Civil, el poder irrevocable tiene un plazo máximo de un año, por lo cual el poder a ser otorgado por A no puede iniciar su vigencia inmediatamente; de lo contrario, vencería mucho antes de terminado el primer periodo de opción de cinco años. 
- Posible contraprestación

Aunque el TUO no establece que el contrato de opción sea oneroso, es la práctica usual en la industria minera que se pacte una contraprestación a favor del concedente por el otorgamiento de la opción. Dicho pago compensaría los posibles costos de oportunidad por perder otras posibilidades de hacer negocios.

- Requisitos para ejercer la opción

Es común que el ejercicio de la opción en el tipo de escenario en que nos encontramos esté condicionado a que $B$ cumpla con un cronograma de inversiones con un monto, hitos y plazos definidos para la ejecución de la exploración, los cuales se encontrarán detallados en el contrato de cesión minera que acompañe al COT. Esto tiene por objetivo asegurar que se incremente el valor del proyecto, dado que al avanzar las actividades de exploración se tendrá mayor conocimiento de las características del yacimiento.

- Ejercicio de la opción

Es muy importante establecer el mecanismo como se ejercerá la opción: si será por correo electrónico, comunicación simple o notarial, así como el plazo para ello. Usualmente se establece con precisión día y hora hasta cuando es posible ejercer la opción.

\section{Contrato de cesión minera}

El contrato de cesión minera (en adelante, CCM) tiene por objetivo otorgar a B un título habilitante que le permita realizar las actividades de exploración en las concesiones que son de titularidad de A, para determinar si en ellas existe un yacimiento que sea económicamente explotable y así ejercer la opción. Los contratos de cesión minera permiten desdoblar en dos personas diferentes dos atributos que usualmente se encuentran en una sola: el de titular de la concesión minera y el de titular de la actividad minera ${ }^{19}$. Las cláusulas que deberían incluirse en el CCM son las que mencionamos a continuación.

19 Se entiende como titular de la actividad minera a aquella persona natural o jurídica que realiza directamente actividades mineras, obteniendo los correspondientes permisos administrativos y certificaciones ambientales a su nombre, y siendo, frente al Estado, responsable por el cumplimiento de las obligaciones ambientales y administrativas de acuerdo con la ley. En consecuencia, no siempre el titular de una concesión minera asume las responsabilidades administrativas y ambientales por las actividades mineras llevadas a cabo en su concesión, salvo que sea también titular de la actividad minera; ello es consecuencia de celebrar un contrato de cesión minera. Por el contrario, en caso de que el titular de una concesión minera efectúe directamente en su concesión actividades mineras, tendrá ambas calidades: de titular de la concesión minera y de las actividades mineras. 
- Mecanismo de protección de las concesiones

De acuerdo con el TUO, los titulares de concesiones mineras están obligados a cumplir dos obligaciones esenciales para mantenerlas vigentes: el pago del derecho de vigencia ${ }^{20}$ y obtener una producción mínima ${ }^{21}$ o pagar las penalidades ${ }^{22}$ aplicables en caso de que no se cumpla con dicha obligación. El incumplimiento de estas obligaciones por dos años trae como consecuencia la caducidad de las concesiones y, por lo tanto, su extinción; en este caso, el Instituto Geológico, Minero y Metalúrgico (INGEMMET), en su momento, declarará el área cubierta por dichas concesiones de libre denunciabilidad y puede ser solicitada por cualquier tercero, con excepción del titular ${ }^{23}$. Se desprende que las consecuencias por incumplir estas obligaciones son fatales en el desarrollo de un proyecto minero, dado que, si las concesiones caducan, no existirá la base sobre la cual este negocio se realizará.

En consecuencia, el CCM debe establecer cláusulas que permitan asegurar el cumplimiento de dichas obligaciones para evitar la caducidad de las concesiones. De acuerdo con el segundo párrafo del artículo 166 del TUO, por la cesión minera el cesionario (en este escenario, B) se sustituye en todos los derechos y obligaciones que tiene el cedente (es decir, A), en calidad de titular de la concesión. Por lo tanto, en este caso, B será quien, frente al Estado, deberá cumplir con las obligaciones antes indicadas. Para asegurar ello, recomendamos lo siguiente ${ }^{24}$ :

i. Que se establezca para B una fecha de cumplimiento o acreditación de cumplimiento de estas obligaciones, con una anticipación razonable al vencimiento del plazo (por ejemplo, un mes), y que se acredite dicho cumplimiento documentalmente ${ }^{25}$. De no cumplir ello, A estaría facultado

20 El derecho de vigencia consiste en un pago anual que se calcula con base en el área de una concesión minera. Por ejemplo, para la gran y mediana minería, el pago de este derecho se calcula en tres dólares por año y por hectárea.

21 La producción mínima consiste en acreditar ventas del mineral extraído de una concesión en una cantidad determinada, en función del valor de la unidad impositiva tributaria (UIT) y del área de la concesión. Para el caso de la gran y mediana minería, la producción mínima se calcula con base en una UIT por año y por hectárea. Esta obligación es exigible a partir de finalizado el décimo año contado desde el 1 de enero del año siguiente al otorgamiento de la concesión.

22 La penalidad aplicable para la mediana y gran minería equivale al $2 \%, 5 \%$ y 10 \% de la producción mínima aplicables de manera escalonada entre el año décimo primero y el vigésimo año contados desde el 1 de enero del año siguiente a haber sido otorgada la concesión.

23 En este caso, el titular estará impedido de solicitar la misma área por dos años.

24 Descartamos la alternativa de fijar una penalidad por el incumplimiento de estas obligaciones, dado que, si bien es cierto que incentivan el cumplimiento, de no lograrse dicho fin, las concesiones podrían caducar y ello impediría la continuación del negocio.

25 El plazo para el pago del derecho de vigencia se inicia el 1 de enero de cada año y termina el último día hábil de junio. La acreditación de la producción mínima se realiza en el mes de junio de cada año según un cronograma establecido en función de los últimos dígitos del RUC de los titulares. El pago de la penalidad por no producción tiene los mismos plazos que el derecho de vigencia. 
a cumplir directamente tales obligaciones y luego pedir el reembolso a $\mathrm{B}$. Cabe mencionar que este mecanismo procedería solo para el caso del pago del derecho de vigencia y penalidades por la falta de producción mínima, mas no para la acreditación de producción mínima, dado que esta es una obligación personalísima a cargo del cesionario ${ }^{26}$.

ii. Que se cree un fondo que permita el pago de las obligaciones antes indicadas para que, si no fueran cumplidas por B en el plazo indicado en el punto anterior, A pueda disponer de dicho fondo para el pago. La ventaja de este mecanismo, en comparación con el anterior, es que A no desembolsaría los fondos de su patrimonio.

iii. Que se establezca como condición resolutoria expresa la falta de cumplimiento de un año en el pago del derecho de vigencia o de penalidades por incumplimiento de producción mínima, con el correspondiente pago de una indemnización cuyo monto podría estar establecido en una cláusula penal.

- Plazo de actividades de exploración y compromiso de inversión

Será de interés de A el asegurar que la exploración pendiente sobre las concesiones se realice en el menor plazo posible y, de la misma manera, que se ejecute una inversión determinada, dado que, como explicamos anteriormente, ello aumentará el valor de las concesiones. Para ello, se recomienda lo siguiente:

i. Que se establezca un monto mínimo de inversiones en exploración y que, adicionalmente, el cumplimiento de dicho monto sea un requisito para ejercer la opción.

ii. Que se establezca un cronograma de actividades de exploración detallado, con hitos y plazos de ejecución, pactando penalidades por retraso.

iii. Que se establezca un área target específica para la exploración, dado que en muchos casos el área objeto de este tipo de transacciones es muy grande, por lo cual es necesario enfocar las inversiones y actividades de exploraciones en las áreas más importantes.

iv. Que se establezcan mecanismos de supervisión de las actividades de exploración en beneficio de A para que de esta manera se asegure el cumplimiento de los puntos anteriores. Usualmente, en estos casos, se suele crear un comité de exploraciones compuesto por representantes de las partes para adoptar en conjunto o por mayoría ciertas decisiones sobre las actividades

26 En el escenario 1 no sería aplicable la acreditación de producción mínima, dado que por la etapa del ciclo minero en la que se encuentra no hay producción. 
de exploración, brindar recomendaciones; o, en ciertos casos especiales, ejercer derechos de veto sobre decisiones importantes.

- Contraprestación por la cesión minera

Según el artículo 166 del TU0, el contrato de cesión minera es oneroso, pues el cedente percibe una compensación. En el escenario 1, en el que la cesión minera es un paso hacia la transferencia de las concesiones, podría pactarse en contra y establecerse que la cesión sea a título gratuito o, en todo caso, pactar una compensación simbólica. Sin embargo, en los casos en que la cesión minera tenga como objetivo una vocación de permanencia y que sea el modelo de negocio elegido por las partes para desarrollar el proyecto, tendría que regularse en detalle el pago de la contraprestación por la cesión, y las partes deben determinar si esta consistirá en el pago de un monto fijo o un monto variable. Remitimos a nuestros comentarios, más adelante, sobre el pago del precio por la transferencia de las concesiones para dar más detalles sobre este aspecto.

- Cesión parcial

El citado artículo 166 del TUO establece que, mediante la cesión minera, el cedente se aparta de todos los derechos y obligaciones que le otorgan las concesiones cedidas, sustituyéndolo el cesionario. En consecuencia, la cesión minera es total, no pudiendo pactarse una cesión minera parcial (ya sea respecto de los derechos u obligaciones o del área), lo cual puede generar inconvenientes, entre otros, en dos posibles escenarios.

Supongamos que, por ciertas razones, A quiere asegurarse de que a través de la cesión minera B no pueda realizar actividades de explotación en las concesiones. En este caso, no podrá incluir en el CCM una cláusula que incorpore la correspondiente obligación de no hacer, dado que la inscripción de este contrato sería observada al contravenir lo dispuesto en el artículo 166 antes citado. Para tal caso, lo que podría recomendarse es que, en un contrato distinto, B se obligue a no realizar actividades de explotación y que, si incumpliera, pague una penalidad, que estaría garantizada mediante una carta fianza u otro tipo de garantía de realización inmediata.

En otro escenario, imaginemos que A está desarrollando actividades de explotación en una de las concesiones objeto de este negocio, pero aun así tienen interés en que parte de dicha concesión sea explorada por B. Según lo antes mencionado, no podría incorporarse una cláusula en el CCM para ceder una parte del área de dicha concesión, pues la cesión implica transferir todos los derechos y obligaciones sobre las concesiones. En tal caso, recomendaríamos lo siguiente: (i) que B realice las actividades de exploración sobre la concesión en 
cuestión en cabeza de A, para lo cual actuaría como un contratista. En este caso, A tramitaría todos los permisos administrativos y la aprobación del correspondiente instrumento de gestión ambiental, siendo responsable ante el Estado por cualquier responsabilidad administrativa, civil o penal, por lo que se deberán pactar las correspondientes obligaciones de B para mantener indemne a A en caso de posibles contingencias; o (ii) dividir la concesión en cuestión, de ser ello técnicamente posible sin interferir en las actividades de explotación, para que el área que sería explorada por B sea parte del negocio, excluyendo el área objeto de explotación por A.

- Información obtenida

Un tema que debe abordar el CCM es la propiedad de la información obtenida como resultado de la exploración. La práctica usual es que, en este caso, A se quede con la información obtenida sin obligación de pago alguno si el negocio no se concreta y $B$ no adquiere las concesiones. Sin embargo, puede pactarse en contra, ya sea para que A pague una contraprestación o para que sea B quien tenga derecho exclusivo sobre dicha información.

\section{Contrato de transferencia}

El contrato de transferencia (en adelante, el CT) marca la última etapa del escenario 1 e implica que la exploración sobre las concesiones arrojó resultados positivos, habiendo decidido B ejercer la opción. Los aspectos que deberían regularse en este contrato son los que mencionamos a continuación.

- Precio de transferencia (monto fijo y monto variable)

La valorización de concesiones mineras para fijar el precio de su transferencia presenta dificultades, pues se basa en el valor del yacimiento que se calcula, entre otras cosas, sobre la base de la cantidad de mineral, los costos de producción y la cotización de los minerales en un momento dado. Considerando que un proyecto de explotación puede durar entre treinta y cincuenta años, calcular el valor de un yacimiento en función de dichas variables es muy complicado. Por ello, usualmente se pacta por la transferencia de concesiones mineras el pago de un monto fijo y un monto variable. El primero se establece por el valor de las concesiones, de acuerdo con la inversión realizada en un momento determinado, y para el segundo, se pacta una regalía contractual, conocida también como regalía NSR (net smelter return). La explicación de lo que es esta regalía, sus características, naturaleza jurídica y otros aspectos bien puede ser objeto de otro trabajo debido a su complejidad. Para efectos de estos comentarios, indicamos que la regalía NSR consiste en el pago de un porcentaje del valor de 
ventas por los minerales producidos de una concesión, menos determinados conceptos como, por ejemplo, los costos de producción o transporte, entre otros, que pueden ser pactados por las partes. En relación con el pago de las regalías, es recomendable incluir en el contrato de transferencia cláusulas que regulen lo siguiente:

i. El porcentaje de la regalía, que se calculará sobre el total de las ventas de minerales en cierto periodo. Usualmente dicho porcentaje oscila entre 0,5 y $3 \%$ pagado de manera anual.

ii. El momento desde el que se inicia la obligación del pago de las regalías. Lo usual es que esta obligación se active una vez que comienza la producción, es decir, la extracción de minerales. Sin embargo, también es común pactar un periodo de gracia y que el pago de las regalías sea exigible a partir de cierto tiempo contado desde que empieza la producción.

iii. El plazo para el inicio de la producción en las concesiones transferidas, ello en razón de que el pago de las regalías contractuales está en función del inicio de la producción. Este plazo se calcula en función de muchos factores como, por ejemplo, la obtención de los permisos legales, el tiempo estimado de construcción de la planta e infraestructura y la obtención de licencia social de las comunidades aledañas al proyecto.

iv. En relación con el punto anterior, es conveniente incluir una cláusula de caso fortuito, en la que se indique expresamente que tendrá tal condición el hecho de que las comunidades aledañas al proyecto no otorguen la licencia social correspondiente o los derechos de acceso al área de las concesiones, en caso de que sean las propietarias, lo cual afecta el cumplimiento de los plazos para culminar la exploración.

v. La obligación de pagar de manera adelantada la regalía. En ciertos casos, puede no ser posible establecer con precisión el plazo en el que se iniciará la producción, pues ello obedece a factores de diversa índole que no siempre están bajo control del obligado (por ejemplo, obtener la licencia social, la cotización de los minerales, conseguir financiamiento, la aprobación de permisos administrativos, entre otros). Por ello, podría pactarse que B pague de manera adelantada un monto fijo, por ejemplo, anual, a cuenta de la regalía en caso de que no se inicie la producción en un plazo determinado. De esta manera, A no se vería perjudicado con un retraso en el inicio de la explotación y, al mismo tiempo, B tampoco se vería perjudicado, dado que el pago adelantado se imputaría al pago de las regalías a devengarse en el futuro. En este caso, se deberá establecer a partir de qué momento desde celebrado el CT se pagará el adelanto. 
vi. Establecer mecanismos de fiscalización a favor de A para asegurar que el cálculo de las regalías se esté haciendo de manera adecuada. Para ello, B estará obligado a entregar las liquidaciones de venta y documentos que sustenten dichas operaciones, así como cierta información contable, todo ello bajo la protección de un convenio de confidencialidad. Esta información sería entregada con cierta periodicidad y bajo un formato definido que permita su fácil procesamiento.

vii. La posibilidad de B de "comprar" la regalía. Considerando que el pago de la regalía puede involucrar para $B$ una serie de cargas administrativas (entre otros, entrega de información y fiscalización por parte de A), suele incluirse en los contratos de transferencia la posibilidad de que $B$ reemplace la obligación del pago de la regalía con el pago de una única suma. Esta es una suerte de compra de la regalía que permitiría a $B$ desvincularse de $A$, y a este, la posibilidad de contar con un capital interesante que le permita desarrollar otros proyectos. Para que se cumpla con tal objetivo, el monto que reemplace a la regalía debería considerable. Será posible pactar que tenga la discreción para decidir la "compra" de la regalía A o B.

viii. La obligación de ambas partes de inscribir la regalía como una carga en las partidas electrónicas de las concesiones, para efectos de la correspondiente publicidad registral.

ix. La obligación de B de que, si transfiere las concesiones a un tercero, incluya en el contrato de transferencia correspondiente la obligación del tercero de pagar la regalía pactada a favor de A, y que este conserve las facultades de fiscalización del cálculo de la regalía respecto del tercero. Existe un debate en la doctrina sobre quién sería el obligado a pagar a favor de A la regalía en caso de transferencia de las concesiones a un tercero. Por un lado, se sostiene que por la naturaleza del negocio minero debería ser el tercero adquiriente, dado que este será el que explote las concesiones, venda los minerales extraídos y calcule el monto de la regalía, más aún si la regalía está inscrita y goza de publicidad registral. Por otro lado, se sostiene que debería ser B el que pague la regalía, puesto que, por el principio de res inter alios acta, los contratos surten efectos solo entre las partes que los celebran, por lo que, no teniendo ninguna vinculación el tercero adquiriente con $\mathrm{A}$, el primero no tendría obligación alguna frente al último. Para evitar la contingencia de establecer quién pagará la regalía en caso de transferencia de las concesiones a un tercero, recomendamos incluir la cláusula que mencionamos en este acápite, aun cuando no es la práctica común hacerlo según los diversos contratos de transferencia que hemos tenido la oportunidad de revisar. 
- Mecanismos de protección de las concesiones

El pago de la regalía contractual a favor de A dependerá en gran parte de la vigencia de las concesiones; si estas se extinguen, no existiría ningún proyecto de explotación. Por ello, será necesario incluir en el CT los mecanismos de protección de las concesiones que hemos comentado para el $\mathrm{CCM}^{27}$.

\section{Escenario 2}

Planteemos ahora un escenario 2, en el que A completó las labores de exploración, desarrolló el proyecto y se encuentra actualmente en explotación de las concesiones, y B está interesado en adquirir ese proyecto. En tal escenario, de concretarse esta transacción, será necesario únicamente celebrar un contrato de transferencia de las concesiones, siendo aplicables nuestros comentarios sobre el CT. Eventualmente podría celebrarse un contrato de opción de transferencia si, por ejemplo, B requiriese previamente realizar una due diligence del proyecto y quisiera asegurar la posibilidad de adquirir el proyecto durante el plazo que dure dicho estudio.

Antes de finalizar estos comentarios, es necesario tomar en cuenta que nuestras propuestas de cláusulas se materializarán a través de la implementación de obligaciones de dar, hacer y no hacer, las cuales, a su vez, deberían ser acompañadas por mecanismos de garantía que permitan asegurar o incentivar su cumplimiento, determinados sobre la base de la naturaleza de las obligaciones que garanticen, así como de las características particulares de cada proyecto y de las partes involucradas.

\section{CONCLUSIONES}

Los negocios mineros en las etapas de exploración y explotación/procesamiento que consisten en la transferencia de proyectos mineros requieren regular contractualmente ciertos aspectos que deben ser incluidos en los contratos mineros de opción, cesión minera y transferencia de concesiones. Los mecanismos propuestos en este trabajo para asegurar los intereses de las partes se han planteado sobre la base de escenarios generales, por lo cual deberán ser ajustados a cada escenario particular, considerando que cada proyecto tiene sus propias dificultades y requerimientos, así como también las partes que intervienen. Se debe tomar en cuenta que una adecuada regulación contractual de este tipo de transacciones es un factor muy importante para asegurar su éxito y prevenir contingencias.

27 En este escenario, sí sería aplicable la exigencia de acreditar una producción mínima, con lo cual nuestra propuesta sobre el cumplimiento de esta obligación no sería aplicable. 
Finalmente, como puede apreciarse de las dificultades planteadas, una adecuada regulación contractual de los escenarios descritos no solo requiere de la aplicación de los aspectos regulatorios mineros, sino también civiles, tributarios, corporativos, entre otros, así como del conocimiento del negocio minero y las dificultades que enfrenta, por ejemplo, el ciclo minero, la valorización de proyectos mineros, de las concesiones, los aspectos sociales, etcétera. Por ello, los profesionales del derecho que ejerzan en este sector deben tener conocimiento de todos estos aspectos para brindar una asesoría integral y de utilidad para sus clientes.

\section{REFERENCIAS}

Código Civil. Decreto Legislativo 295 de 1984. 24 de julio de 1984 (Perú). https://www. oas.org/juridico/PDFs/mesicic4_per_cod_civil.pdf

Constitución Política del Perú. 30 de diciembre de 1993 (Perú). http://www.pcm.gob.pe/ wp-content/uploads/2013/09/Constitucion-Pol\%C3\%ADtica-del-Peru-1993.pdf

Decreto Supremo 014-92-EM de 1992 [Ministerio de Energía y Minas]. Texto Único Ordenado de la Ley General de Minería. 2 de junio de 1992. http://www.minem. gob.pe/minem/archivos/file/Mineria/LEGISLACION/TU0\%20.pdf

Decreto Supremo 03-94-EM de 1994 [Ministerio de Energía y Minas]. Reglamento de Diversos Títulos del Texto Único Ordenado de la Ley General de Minería. 14 de enero de 1994. https://www.peru.gob.pe/docs/PLANES/94/PLAN_94_DS\%20 N\%C2\%BA\%2003-94-EM_2008.pdf

Ministerio de Minas y Energía de Colombia. (2015). Glosario técnico minero. https:// Www.minenergia.gov.co/documents/10180/698204/GLOSARIO+MINERO+F INAL+29-05-2015.pdf/cb7c030a-5ddd-4fa9-9ec3-6de512822e96

Ravines, R. (1987). El Cuarto del Rescate de Atahualpa 1532-1986. Instituto Nacional de Cultura.

Resolución Superintendencia Nacional de los Registros Públicos 052-2004-SUNARP-SN. Reglamento de Inscripciones del Registro de Derechos Mineros. 1 de febrero del 2005.

Seinfeld, J., Cuzquén, G., Farje, G., y Zaldívar, S. (1998). Introducción a la economía de los recursos naturales y del medio ambiente. Universidad del Pacífico, Centro de Investigación. 
